\title{
Desenvolvendo Empreendedores e Criando Startups no curso de Sistemas de Informação
}

\author{
Luiz Melo Romão, Marcelo Leandro de Borba, Vanessa de Oliveira Collere \\ ${ }^{1}$ Departamento de Informática - Universidade da Região de Joinville (UNIVILLE) \\ Caixa Postal 246 - 89.219-710 - Joinville - SC - Brasil \\ luiz.melo, marcelo.leandro, vanessa.collere@univille.br
}

\begin{abstract}
The concept of Entrepreneurial University emerges as a response to the new demands of society, expanding their interactions and creating innovative environments. In this regard, since 2014, the Bachelor in Information Systems at Univille in partnership with the Incubator Inovaparq, has been offering to its academics the Program of Entrepreneurship Development and Creation of Startups. The program's goal is to propose to the students a new way of thinking and build innovative products and services that lead to a sustainable business. The program is divided into 13 steps that help from the business ideas conception until validation with the market and has received more than 80 proposals. The program is a tool that has managed to sensitize a large number of academics, prospecting innovative proposals and qualifying future entrepreneurs with current concepts of economic and social development with environmental sustainability.
\end{abstract}

Resumo. O conceito de Universidade Empreendedora emerge como uma resposta às novas demandas da sociedade, ampliando suas interações e criando ambientes de inovação. Neste sentido, desde 2014, o Bacharelado em Sistemas de Informação da Univille em parceria com a Incubadora do Inovaparq, vem oferecendo para seus acadêmicos o Programa de Desenvolvimento do Empreendedorismo e Criação de Startups. O objetivo do programa é propor para os acadêmicos um novo modo de pensar e de construir produtos e serviços inovadores que levem a um negócio sustentável. O programa é dividido em 13 etapas que auxiliam desde a concepção de ideias de negócios até a sua validação com o mercado e já recebeu mais de 80 propostas. O programa é uma ferramenta que vem conseguindo sensibilizar um grande número de acadêmicos, prospectando propostas inovadoras e qualificando futuros empreendedores com conceitos atuais de desenvolvimento econômico e social com sustentabilidade ambiental.

\section{Introdução}

Joinville é a maior cidade de Santa Catarina, conhecida principalmente por ser o maior polo metalúrgico e industrial de ferramentarias do Brasil, e também uma das principais forças no país no desenvolvimento de softwares. Empresas como Totvs (antiga Datasul), Neogrid, Linx entre outras, despertam nos jovens o interesse em desenvolver sua carreira profissional na área da informática.

O Departamento de Informática da Universidade da Região de Joinville (Univille), que completou 20 anos em 2016, vem, ao longo destes anos, contribuindo para a formação 
de profissionais comprometidos com a produção do conhecimento científico e no desenvolvimento de produtos e processos de software dentro da perspectiva da melhoria contínua da qualidade, auxiliando na capacidade de crescimento deste setor na cidade.

Entretanto, aliado ao comprometimento em formar profissionais de qualidade para o mercado, é importante que os cursos de graduação fiquem atentos às novas competências que a sociedade vem demandando devido as constantes e complexas transformações que o mundo vem passando. Para [Souza and Aquino Guimarães 2005] o desenvolvimento tecnológico, que é o grande responsável pelas mudanças e transformações, fornece estímulo e cria a visão para o espírito empreendedor e a inovação na sociedade, fazendo com que as pessoas e as empresas busquem novas direções e novas conquistas [Audy 2006]. Desta forma, o conceito de empreendedorismo está diretamente relacionado com criatividade e inovação.

Para atender as necessidades atuais da sociedade, as universidades precisam estar em equilíbrio criativo com o ambiente, preparadas para as mudanças e criando espaços propícios para a inovação. A academia tem recebido diversos sinais, tanto do ambiente externo como do seu ambiente interno, que apontam para pressões crescentes por uma renovação da Universidade para fazer frente às novas demandas [Audy 2006].

Conviver em ambientes favoráveis à cultura empreendedora pode ser bastante vantajoso para os acadêmicos que buscam desenvolver seu perfil empreendedor, pois encontram pessoas com o mesmo espírito e características, possibilitando interações promissoras para seus projetos. Estes ambientes oferecem estímulos ao desenvolvimento empreendedor nas várias fases da empresa, desde o nascimento da ideia até a consolidação de uma grande organização com foco em tecnologia e inovação [Romão et al. 2016].

Para [Aguiar 2013], o empreendedorismo em universidades pode trazer grandes benefícios tanto para os centros de pesquisa e seus alunos, como para as empresas. $\mathrm{O}$ autor complementa que no mundo, a percepção de que o empreendedorismo poderia ser ensinado, começou a circular nos anos 1970 e 1980 especialmente nos Estados Unidos, e os resultados podem ser vistos por exemplo em: Babson College, Stanford e Baylor University. No Brasil, as universidades já começam a perceber esse movimento e instituições como Unicamp, USP, Mackenzie entre outras, vem atuando cada vez mais no tema e o número de atividades e cursos focados no empreendedorismo aumentam ano a ano.

O Departamento de Informática da Univille, engajado neste movimento e percebendo que sua contribuição para a sociedade vai além de formar bons profissionais para o mercado, incluiu no perfil profissiográfico do curso de Sistemas de Informação, o desenvolvimento de competências relativas aos fundamentos da inovação, da gestão e do empreendedorismo, criando desta forma, mecanismos importantes para estimular o comportamento empreendedor nos acadêmicos. Desde 1999, a disciplina de empreendedorismo faz parte da grade curricular do curso e o departamento vem desenvolvendo uma série de projetos com o objetivo de contribuir para a formação de um ambiente promotor da cultura empreendedora e para o surgimento de empreendimentos sustentáveis, por meio da estruturação de ações que integrem as competências e potenciais existentes na universidade.

Com a proposta de propiciar um contato ainda mais próximo dos acadêmicos com conceitos ligados ao empreendedorismo e com o desenvolvimento de novos negócios, o 
Departamento de Informática da Univille, em parceria com a Incubadora de Empresas de Base Tecnológica do Parque de Inovação Tecnológica de Joinville e Região (IBT Inovaparq), criou em 2014, o Programa de Desenvolvimento do Empreendedorismo e Criação de Startups (PDECS). Este programa foi concebido com o objetivo de proporcionar espaço, qualificação e experiência para os acadêmicos interessados em desenvolver projetos inovadores, que, futuramente, podem se transformar em novas startups. O programa é pautado com foco nas práticas da Startup Enxuta. A premissa é criar um ambiente de aceleração onde, durante todo programa, os acadêmicos do curso de Sistemas de Informação, sejam estimulados a validar seu projeto com possíveis clientes e testar alternativas até chegar a um produto preparado para o mercado.

O PDECS é coordenado pelo Gerente da IBT - Inovaparq, que também é professor do departamento, e conta com o apoio de mentores e dos próprios empreendedores que fazem parte da incubadora. O PDECS é oferecido como uma atividade extracurricular e os alunos de todos os períodos são estimulados a participar do programa. O programa é apresentado para os acadêmicos nas aulas inaugurais e nos diversos eventos de empreendedorismo que o departamento promove durante o ano.

O programa é dividido em 13 etapas que auxiliam desde a concepção de ideias de negócios até a sua validação com o mercado. Este artigo tem como objetivo descrever com detalhes o modelo do PDECS, assim como as atividades desenvolvidas e os resultados obtidos até agora. O artigo, além desta introdução, apresenta na seção 2 uma análise referente à importância do conceito de Universidade Empreendedora e do estímulo ao empreendedorismo na academia. Na seção 3, são apresentados o PDECS e as etapas que compõem o programa. Na seção 4 são apresentados os resultados obtidos com o programa e na última seção, as considerações finais do artigo.

\section{Universidade Empreendedora}

Com a sociedade se desenvolvendo na era do conhecimento, as empresas vêm mudando suas características e o mercado de trabalho vai se tornando mais intensivo em conhecimento, gerando demandas por um novo tipo de profissional. Ao mesmo tempo, a sociedade passa a esperar mais das universidades, em termos de contribuições ao processo de desenvolvimento econômico e social. Os problemas se tornam mais complexos e o ambiente mais incerto. Neste contexto, as demandas da sociedade crescem constantemente e a capacidade de responder a estas demandas desequilibra-se [Audy 2006].

O modelo da hélice tríplice [Etzkowitz 2008], explicita a necessidade da interação entre universidade, empresa e governo como chave para a inovação e o crescimento da economia baseada no conhecimento. Portanto, é necessária a existência de atores relevantes que representam cada uma destas esferas e que ocorram interações e relações entre estes atores, compondo uma rede.

Conforme [Etzkowitz and Viale 2010] a sociedade moderna está na terceira revolução acadêmica. A primeira e a segunda revolução, integraram a pesquisa e o desenvolvimento econômico e social como missões da universidade, enquanto que a terceira diz respeito à criação da Universidade Empreendedora, que passa a ser o centro gravitacional para o desenvolvimento econômico e da criação e difusão do conhecimento, tanto nas sociedades industrialmente avançadas quanto naquelas em desenvolvimento. Os autores argumentam que a Universidade Empreendedora além de ciência, faz também tecnologia 
e cada vez mais inovação. Estas observações demonstram a ampliação do papel da universidade no contexto da sociedade do conhecimento e o incremento de sua relevância em termos da influência que exerce nos ambientes nos quais está inserida.

Neste sentido, o conceito de Universidade Empreendedora emerge como uma resposta às novas demandas da sociedade. Mas este conceito é ainda muito controverso no meio acadêmico, apresenta grandes desafios e envolve uma série de outros conceitos relevantes associados, tais como inovação, criatividade e risco. A busca por uma Universidade mais flexível e com capacidade de adaptação às mudanças é um desafio que muitas instituições estão enfrentando [Audy 2006].

Para atender a estas demandas é importante que as universidades ampliem suas interações com as empresas, governos e instituições, criando ambientes de inovação, que dentre outras ações, estimulem e acolham as empresas nascentes. [Clark 2003] identifica como questões críticas do processo de mudança, a necessidade de desenvolvimento de novas estruturas e mecanismos institucionais, como centros de pesquisa interdisciplinares, ambientes de inovação, parques tecnológicos, incubadoras, entre outros. Além disso, o autor ainda complementa como fatores importantes, o estímulo aos acadêmicos que devem ser incorporados no processo de transformação e no desenvolvimento de uma cultura empreendedora integrada, representada por uma visão compartilhada e gerando uma perspectiva institucional.

Em 2014, o Sebrae em conjunto com a Endeavor desenvolveu uma pesquisa a respeito do empreendedorismo nas universidades brasileiras [Endeavor 2014]. A pesquisa reuniu o depoimento de mais de 4 mil alunos e centenas de professores e avaliou o ensino do empreendedorismo em 70 instituições. Um dos objetivos do trabalho, feito ao longo de quatro anos, foi verificar se a oferta de disciplinas sobre o tema satisfaz a demanda. Buscou também analisar se as universidades brasileiras estão preparadas para lidar com aulas cada vez mais cheias de estudantes que se veem no futuro, não como altos executivos, mas como fundadores de startups, varejistas ou donos de franquias.

Segundo a pesquisa, a primeira parte da resposta aponta um cenário animador, 92\% das instituições de ensino afirmaram possuir algum curso, programa ou iniciativa relacionados ao tema. A segunda parte, no entanto, indica que ainda falta fazer muita coisa, pois para 95\% dos estudantes, as disciplinas sobre o assunto estão mal distribuídas, o que mostra que apesar das iniciativas existentes, muito ainda precisa ser revisto. A pesquisa ainda revela que do total de alunos entrevistados $62,6 \%$ tem interesse em ser empreendedor, sendo que para os alunos da área de TI, este número aumenta para com $66,5 \%$ de potenciais empreendedores. Conforme mostra a figura 1, o número de alunos interessados na criação de novos negócios vem crescendo nos últimos anos.

O governo também vem desenvolvendo iniciativas. A Lei de Inovação, criada em 2004, vem contribuindo para o desenvolvimento tecnológico do país ampliando parcerias entre universidades e empresas. Conforme [Aguiar 2013], os Núcleos de Inovação Tecnológica (NITs) são uma das maneiras de tentar estabelecer melhores relações entre institutos de pesquisa e o setor produtivo. Nesses núcleos são detectados resultados de pesquisas com potencial para patentes, entretanto, ainda é observada resistência por parte dos pesquisadores. Muitas vezes, a preferência é pela publicação de um artigo científico, tornando o conhecimento público, e sem a proteção da patente, qualquer empresa pode se 


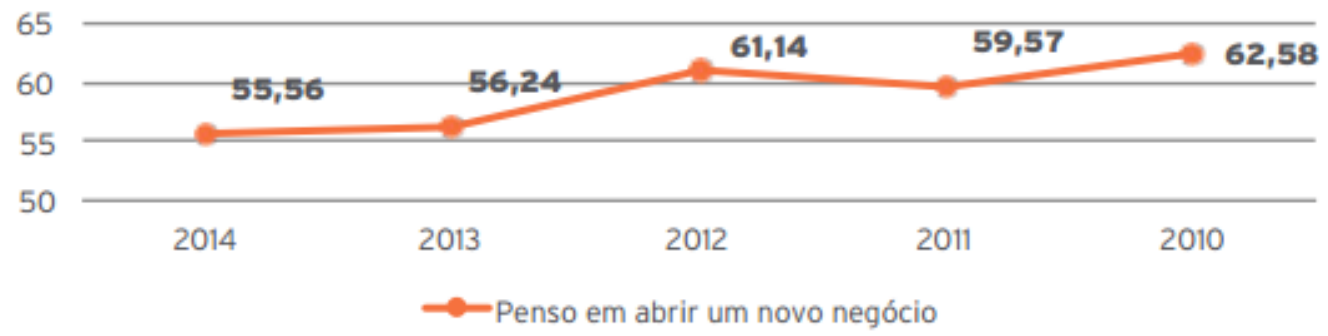

Figura 1. Alunos que pensam em abrir um novo negócio (\%) [Endeavor 2014]

apropriar da ideia e, caso o faça, o Brasil é forçado a pagar royalties para reproduzi-la.

Para [Aguiar 2013], os NITs buscam a proteção dessas tecnologias produzidas em universidades, podendo gerar lucros e benefícios para o país e para os próprios institutos de pesquisa.

Com isso, aliada a estas ações e estreitamente relacionado ao seu perfil de Universidade Comunitária ${ }^{1}$, a Univille e o Departamento de Informática vêm, histórica e gradativamente, desenvolvendo ações no sentido de adotar uma postura de Universidade Empreendedora. A Fundação Educacional da Região de Joinville, entidade que mantém a Univille, criou em 2009 o Parque de Inovação Tecnológica de Joinville e Região e a Incubadora de Base Tecnológica com o objetivo de proporcionar um ambiente de aproximação entre Universidades, Empresas e Governos que responda aos desafios enfrentados por Joinville e região, de modo a promover o desenvolvimento regional sustentável.

O Parque Tecnológico, juntamente com a Incubadora, oferecem para os cursos de graduação, pós-graduação e toda a comunidade a possibilidade de desenvolvimento da pesquisa aplicada, da inovação, de aproximação com grandes indústrias e do aumento de qualidade dos profissionais que saem da academia. Estes fatores e a criação do Programa de Desenvolvimento do Empreendedorismo e Criação de Startups, definido a seguir, comprovam o engajamento da instituição no processo de transformação e renovação do ambiente acadêmico.

\section{Metodologia do Programa de Desenvolvimento do Empreendedorismo e Criação de Startups (PDECS)}

O PDECS foi criado com o intuito de aproximar os alunos do curso de Sistemas de Informação da Univille com a incubadora, contribuindo para que os acadêmicos possam despertar para o empreendedorismo, se capacitar, e desenvolver novos produtos e soluções inovadoras. A divulgação do programa é realizada em todas as séries do curso de Sistemas de Informação e as propostas podem ser apresentadas na forma individual ou em equipes, com a participação de acadêmicos de outros cursos, sendo que esta modalidade é bastante valorizada, pois consegue unir competências de outras áreas no negócio.

O programa é realizado durante 6 meses e funciona como um acelerador de ideias que possam gerar novos negócios. O foco do programa é colocar em prática os principais

\footnotetext{
${ }^{1}$ Universidades Comunitárias são instituições sem fins lucrativos, que desenvolvem ações essencialmente educacionais, como ensino, pesquisa e extensão, com notória excelência em suas atividades. A este cenário soma-se sua forte vocação social [ABRUC 2016].
} 
conceitos da Startup Enxuta, propondo para os acadêmicos um novo modo de pensar e de construir produtos e serviços inovadores que levem a um negócio sustentável. O PDECS vai até ao ponto onde o empreendedor consegue validar suas hipóteses com relação ao um novo produto ou serviço, definindo seus potenciais clientes e mercado.

A filosofia da Startup Enxuta, foi definida por Eric Ries [Ries 2014] e é baseada na Lean Manufacturing, desenvolvida na década de 1980 pelos fabricantes de automóveis japoneses. Similar aos preceitos do gerenciamento enxuto, a filosofia da Startup Enxuta pretende eliminar práticas de desperdício e aumentar práticas de produção de valor durante a fase de desenvolvimento do produto. Isto faz com que as startups possam ter melhores chances de sucesso sem necessitar de grandes quantidades de financiamento externo, de planos de negócios elaborados ou ainda do "produto perfeito". O autor acredita que o feedback do consumidor durante o desenvolvimento do produto é parte integrante do processo e garante que o empreendedor não invista tempo projetando recursos ou serviços que o consumidor não necessita ou não fará uso no primeiro momento.

A principal ideia da metodologia Startup Enxuta é o ciclo Construir-MedirAprender. O ciclo, como mostra a figura 2, representa o fluxo principal de atividades do método, pelas quais o empreendedor deverá passar antes de decidir se vai "pivotar" ou perseverar. O termo "pivotar" é utilizado na Startup Enxuta e designa a mudança radical nos rumos do negócio. Para alavancar a sua startup, o empreendedor deve conseguir seguir esse ciclo no mínimo tempo possível, ou seja, testando, validando e criando novas hipóteses de uma maneira rápida e contínua

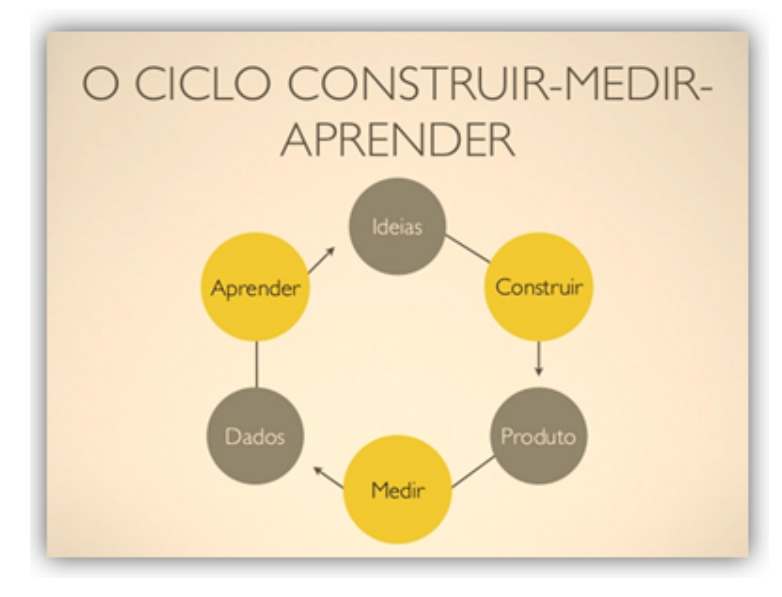

Figura 2. Ciclo Construir-Medir-Aprender [Ries 2014]

O método CONSTRUIR inicia considerando que o empreendedor já identificou um problema a ser resolvido e uma provável solução para este problema. Portanto, a primeira coisa a fazer é construir o produto ou o Produto Mínimo Viável (MVP), que é uma versão de um novo produto que permite à equipe coletar a quantidade máxima de aprendizagem validada sobre clientes, com o mínimo esforço. O objetivo do MPV é testar hipóteses de negócios fundamentais e ajudar os empreendedores a começar o processo de aprendizagem o mais rápido possível.

Em seguida, é necessário MEDIR o experimento, ou seja, verificar se a solução imaginada para o problema é viável em termos técnicos, de negócio e de funcionalidade. 
O objetivo é verificar se os esforços empregados estão se traduzindo em progressos concretos.

Com as medições coletadas passa-se à fase final - APRENDER. Após mensurados os resultados é preciso tomar uma decisão em relação ao projeto: manter a estratégia ou pivotar.

Baseado nestes conceitos, o PDECS foi elaborado e dividido em 13 etapas que devem ser percorridas pelos acadêmicos durante o período do programa. Cada etapa auxilia o futuro empreendedor a entender cada vez mais sobre sua proposta e todas as questões relacionadas ao desenvolvimento de um novo negócio. A figura 3 demonstra as 13 etapas do PDECS que serão detalhadas a seguir.

\section{ETAPA 1 - COLOQUE SUA IDEIA NO PAPEL}

Para fazer parte do programa os acadêmicos devem participar de um edital de seleção. Para se inscrever no edital é preciso preencher um formulário com questões relacionadas ao perfil empreendedor, caracterização da proposta a ser desenvolvida, uma visão dos principais concorrentes, o que o acadêmico espera com relação ao programa e qual será o seu grau de comprometimento. As propostas recebidas são analisadas por uma banca avaliadora e os acadêmicos ainda passam por uma entrevista para que os avaliadores possam tirar alguma dúvida com relação à proposta.

\section{ETAPA 2 - ENCONTRE SUA CAUSA}

Os acadêmicos selecionados iniciam o processo participando de um workshop sobre Inovação Natural. Criado por Eduardo Borba [Borba 2015], este conceito de gestão moderniza a Teoria da Administração transformando empresas em Causas. A busca pela Causa é movida pelo alto engajamento humano por um propósito nobre e faz com que o empreendedorismo seja um propósito de vida. Fazendo aquilo que ama, o empreendedor tem muito mais chances de dar certo. Fundamentado no princípio de Aristóteles que define que "onde cruzam suas paixões e talentos com as necessidades do mundo, aí estará o seu lugar", a Inovação Natural promove o cruzamento para se chegar na Causa, o ponto mais importante do conceito. A proposta principal deste workshop é mostrar para os futuros empreendedores que o fundamental para o sucesso do negócio é que, além da questão financeira, este seja voltado para a contribuição da melhoria de vida da sociedade.

\section{ETAPA 3 - APRENDA OS CONCEITOS DA STARTUP ENXUTA}

Nesta etapa os acadêmicos são apresentados aos conceitos e práticas da Startup Enxuta. A leitura do livro é indicada para um melhor entendimento e para que os acadêmicos possam conhecer os exemplos utilizados pelo autor. O programa segue os conceitos da Startup Enxuta como base, mas é importante que cada participante, juntamente com a gestão do PDECS, encontre também as ferramentas e as práticas mais adequadas para cada negócio.

\section{ETAPA 4 - CAPACITE-SE}

Durante o programa os acadêmicos recebem uma série de capacitações presenciais e no formato EaD para auxiliá-los no empreendimento. Os principais cursos oferecidos pelo programa são: SCRUM (metodologia ágil para gestão e planejamento de projetos), Design Thinking (que engloba um conjunto de métodos e processos para abordar problemas, relacionados à aquisição de informações, análise de conhecimento e propostas de soluções), Business Model Canvas (ferramenta de gerenciamento estratégico, que per- 
mite desenvolver e esboçar modelos de negócio novos ou existentes), Elaboração de Pitch (técnicas de apresentação sumária de 3 a 5 minutos com objetivo de conquistar o interesse da outra parte, investidor ou cliente, pelo seu negócio), Propriedade Intelectual (para auxiliar no entendimento de proteção dos direitos e da importância do registro de propriedade intelectual) e Internacionalização de Empresas (para entender a importância dos aspectos culturais e do comportamento do consumidor internacional e apresentar formas de criação de um plano coeso e prático de internacionalização de startups), considerados conteúdos importantes para o desenvolvimento dos empreendedores e para a criação de startups.

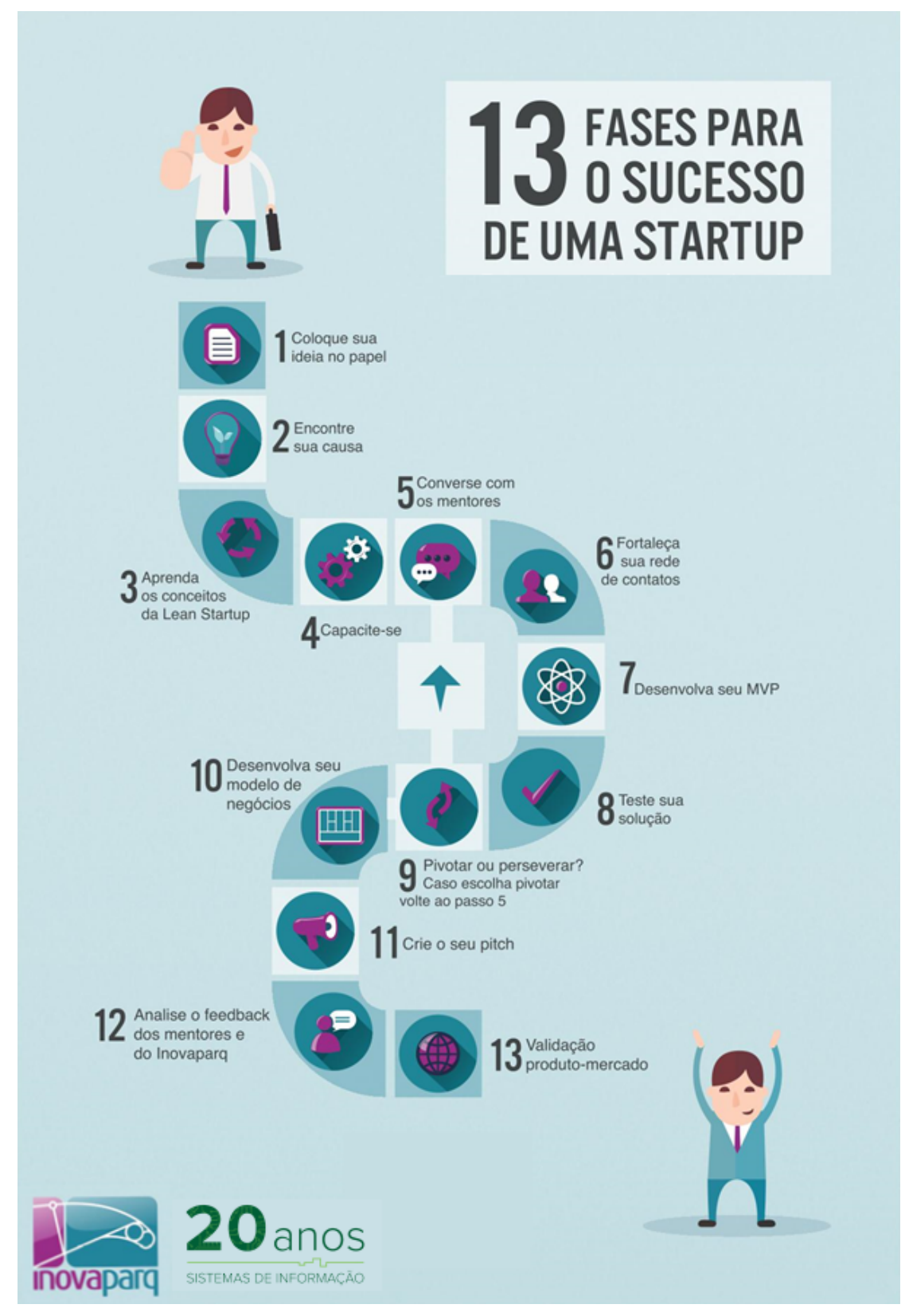

Figura 3. Etapas do PDECS

\section{ETAPA 5 - CONVERSE COM OS MENTORES}

Durante o PDECS, os acadêmicos têm à disposição um grupo de mentores formado por empreendedores de sucesso, especialistas em startups, investidores-anjo e outros profis- 
sionais nas áreas de marketing, finanças, gestão, mercado entre outros, para auxiliar no amadurecimento da ideia. Os mentores, que são voluntários no PDECS, têm papel fundamental no programa, dada a sua experiência de mercado e conhecimento sobre questões ligadas ao empreendedorismo. Os mentores apoiam e direcionam os projetos dos novos empreendedores auxiliando os acadêmicos a verificar questões práticas do dia-a-dia do negócio, como analisar situações críticas, auxiliar no networking e, desafiá-los.

\section{ETAPA 6 - FORTALEÇA SUA REDE DE CONTATOS}

Além do networking criado no programa e também por meio dos mentores, é importante que os acadêmicos fortaleçam e ampliem a sua rede de contatos. Durante o PDECS os acadêmicos participam de reuniões com as empresas da incubadora, onde podem compartilhar suas ideias e trocar conhecimentos com outros empreendedores. Além disso, os acadêmicos são estimulados a participar de feiras, conferências e outros eventos onde eles podem apresentar suas propostas. Conseguir pessoas para trabalhar em startups é uma tarefa bastante complicada, por isso uma rede de contatos qualificada pode ser extremamente valiosa para conseguir colaboradores interessados em participar do negócio. Além disso, as redes sociais são importantes canais de captação de clientes. Por isso, planejamento e pesquisa são os itens essenciais para criar uma boa estratégia de marketing.

\section{ETAPA 7 - DESENVOLVA O SEU MVP}

Nesta etapa os acadêmicos são estimulados a "colocar a mão na massa" e iniciar o seu Produto Mínimo Viável (MVP). O MVP é uma versão do produto com um conjunto mínimo de características necessárias para que ele possa ser colocado de imediato no ar e submetido a testes que permitirão validá-lo e aprimorá-lo. Um MVP possui três características principais: tem valor suficiente para que as pessoas comecem a utilizá-lo, demonstra benefícios suficientes para reter os usuários iniciais, fornece um ciclo de feedback para orientar o desenvolvimento futuro. Esta técnica de desenvolvimento assume que os usuários iniciais podem visualizar o produto final a partir do MVP e que o produto deixa abertura para receber comentários e sugestões para ajudar no desenvolvimento de versões futuras.

\section{ETAPA 8 - TESTE SUA SOLUÇÃO}

Criado o MVP, chega a hora de os acadêmicos testarem suas hipóteses diretamente no mercado, em contato com o seu potencial consumidor. A ideia é buscar o feedback destes clientes para entender o que falta na proposta desenvolvida para fazer dele o melhor produto ou serviço. O objetivo é encontrar o real problema que precisa ser solucionado, conforme indicações do seu potencial cliente. Nesta etapa o programa apresenta aos acadêmicos algumas ferramentas que podem ser utilizadas nesta fase. Entretanto, o mais importante é que os acadêmicos tenham definido o que eles aprenderão com os testes e como os resultados serão utilizados para aperfeiçoar sua proposta.

\section{ETAPA 9 - PIVOTAR OU PERSEVERAR?}

Durante todo o programa os acadêmicos são colocados à prova com relação a proposta que está sendo desenvolvida. Em qualquer momento é possível aos acadêmicos pivotar para abandonar a estratégia original e testar uma nova hipótese. Esta talvez seja uma das decisões mais difíceis no desenvolvimento de um novo negócio, mas é importante deixar claro que quanto mais cedo o empreendedor reconhecer que é o momento de pivotar, menor será o desperdício de tempo e dinheiro. Caso pivotar seja a solução, o acadêmico deve voltar à etapa 5 e recomeçar o processo. 


\section{ETAPA 10 - DESENVOLVA SEU MODELO DE NEGÓCIOS}

Com a proposta definida, os acadêmicos são orientados a desenvolver o seu modelo de negócios baseado no Business Model Canvas, que é uma ferramenta de gerenciamento estratégico, e que permite desenvolver e esboçar modelos de negócio novos ou existentes. É um mapa visual pré-formatado contendo nove blocos do modelo de negócios. O Business Model Canvas define os principais itens que irão constituir a empresa e que deverão ser continuamente revisados ao longo do tempo para saber se cada item está sendo bem atendido ou se é necessário fazer alteração para que se obtenha um melhor resultado. Os itens que compõe o Business Model Canvas são: Proposta de Valor, Segmento de Clientes, Canais, Relacionamento com Clientes, Recursos Principais, Atividades Principais, Parcerias Principais, Receitas e Estrutura de Custos.

\section{ETAPA 11 - CRIE O SEU PITCH}

Com o negócio definido, os acadêmicos desenvolvem um pitch, uma apresentação curta, que deve ter de três a cinco minutos de duração, e que tem o objetivo de despertar o interesse de clientes e investidores no negócio. Neste pitch, devem ser demonstradas, de forma sucinta, todas as informações relevantes da empresa. Para elaborar um pitch que possa ser atraente para os investidores e clientes é importante que os acadêmicos saibam, em poucas palavras, mostrar como o seu negócio soluciona determinado problema, mostrar o mercado potencial, definir o diferencial do seu negócio com relação aos concorrentes, mostrar a experiência da equipe, qual a expectativa de crescimento, planos futuros, e por fim, em caso de apresentação para investidores, qual o valor do investimento buscado pela empresa para cobrir as despesas e determinar sua sustentabilidade por um determinado período e como se espera que ocorra o retorno sobre o investimento.

\section{ETAPA 12 - ANALISE O FEEDBACK DOS MENTORES E DO INOVAPARQ}

Durante todo o processo é importante os acadêmicos analisarem os feedbacks dos mentores e da gestão do programa para auxiliar nas escolhas do dia a dia. Como muitas vezes as propostas são apresentadas por um ou dois acadêmicos, os mentores e a gestão do programa funcionam como conselheiros que auxiliam nas tomadas de decisão e nas orientações das possíveis divergências que eventualmente ocorram entre os sócios.

\section{ETAPA 13 - VALIDAÇÃO (ENCAIXE PRODUTO-MERCADO)}

Esta é a etapa final, é o momento em que os acadêmicos enfim encontram um conjunto amplo de clientes em potencial que querem exatamente o que o produto está oferecendo.

Após o término das 13 etapas, os acadêmicos apresentam os resultados obtidos, as dificuldades enfrentadas e quais são os próximos passos para o desenvolvimento efetivo do novo produto ou serviço que poderá revolucionar o mercado. Neste momento os empreendedores se sentem mais confiantes e é o momento de alçar voos maiores. Nesta fase o Programa de Incubação da IBT - Inovaparq é o caminho natural para os acadêmicos continuarem a ter o apoio para a criação da sua startup.

\section{Resultados obtidos com o PDECS}

O PDECS iniciou sua primeira turma em 2014 e atualmente está executando a terceira edição. O programa é aberto para os acadêmicos que possuem alguma ideia de produto inovador e que resolva problemas em qualquer área utilizando recursos da Tecnologia da Informação e Comunicação.

Para cada turma, a IBT - Inovaparq oferece aos selecionados: ambiente de co- 
working em sala climatizada e equipada com mesas e cadeiras, acesso à Internet, além de estacionamento e infraestrutura em geral. Os acadêmicos devem se comprometer a utilizar o espaço disponibilizado por no mínimo 20 horas mensais e participar de todos as capacitações e reuniões organizadas pela IBT - Inovaparq.

Ao todo o programa já recebeu 84 propostas, que foram avaliadas, das quais 30 foram selecionadas para participar do processo. O acadêmico cuja proposta não é selecionada recebe uma consultoria sobre os pontos que precisam ser ajustados no projeto para dar continuidade na ideia.

Um dos desafios para a coordenação do programa é incentivar os acadêmicos a serem persistentes em suas propostas. O processo faz com que os empreendedores busquem soluções que resolvam problemas e não somente ideias de negócio que se adequam aos interesses dos proponentes. Isso faz com que os projetos necessitem ser adaptados durante o programa, pivotando, para encontrar se existe mercado para a proposta. Este processo de validação-pivotagem constitui-se em um desafio de persistência aos acadêmicos.

Para auxiliar na formação empreendedora dos alunos são oferecidas capacitações presenciais e conteúdos disponibilizados de forma on-line. Os cursos presenciais são ministrados pelos professores da Universidade ou parceiros da incubadora.

A cada duas semanas são organizados encontros onde um determinado tema é discutido. Nestes encontros, além dos acadêmicos, também participam as empresas que fazem parte do Programa de Incubação da IBT - Inovaparq. Isto estimula o networking e a troca de conhecimento entre todos, fazendo com que os acadêmicos possam vivenciar o dia a dia das startups, seus desafios e conquistas.

Outra questão fundamental é o apoio oferecido pelos mentores no programa. $\mathrm{O}$ objetivo do mentor é provocar questionamentos, contribuir com novas perspectivas e expertise, além de compartilhar informações relevantes sobre o mercado e também evitar que os novos empreendedores cometam os mesmos erros cometidos por eles no passado. Nos encontros com os mentores, os empreendedores têm a oportunidade de validar se estão avançando em suas ideias e seguindo para o caminho mais adequado.

Ao final dos 6 meses do programa e com as ideias validas no mercado, os empreendedores têm a oportunidade de apresentar seus projetos finais para uma banca de especialistas e possíveis investidores. Com o término das atividades do PDECS, o caminho natural para os empreendedores é continuar com o desenvolvimento do seu negócio dentro do Programa de Incubação da IBT - Inovaparq, que irá auxiliar, inicialmente na formalização da empresa e no apoio e acompanhamento gerencial do desenvolvimento do empreendimento.

Das duas turmas já finalizadas, somente uma proposta não continuou na incubadora após o término do programa. As outras passaram a integrar o Programa de Incubação da IBT - Inovaparq, onde continuam desenvolvendo os seus negócios e algumas já iniciando as primeiras vendas.

Como destaque podem ser citadas as empresas: Vividisk e Eloverde. A Vividisk desenvolve e comercializa uma solução para impulsionar vídeos de conteúdo potencialmente viral. Esta empresa foi selecionada em 2016 para participar do programa Startup/SC e recebeu um aporte de investidor anjo para a aceleração do seu negócio. O 
programa Startup/SC é um concorrido programa do Sebrae Santa Catarina oferecido para a capacitação de startups de todo o Brasil.

A Eloverde desenvolve um Sistema Integrado de Gerenciamento de Resíduos, foi selecionada para participar do programa de aceleração Inove Senior e também foi uma das empresas selecionadas a participar da primeira etapa do $6^{\circ}$ Concursos Acelera Startup, organizado pela Federação das Indústrias do Estado de São Paulo (FIESP).

Outros fatos que mostram que o PDECS, organizado da forma apresentada, pode ser de grande importância para o bom desempenho das startups, foram obtidos pelos depoimentos dos próprios acadêmicos que participaram do programa. Para os empreendedores da Vividisk, "O programa ajudou no processo de ideação à validação do modelo de negócio, além do excelente aprendizado e networking com outras startups que estão em estágios mais avançados". Na EloVerde, "O programa foi muito importante. No processo conhecemos mentores e tivemos acesso a informações que nos orientaram quanto ao nosso projeto e validação da nossa ideia. Com isso conseguimos formatar nossa proposta e chegar a um MVP ao final do programa. Aprendemos muito com o programa tanto nos aspectos empreendedores como os do produto em si."

\section{Conclusão}

As últimas décadas envolveram profundas mudanças nas universidades que se abriram para as demandas da sociedade, ampliando suas interações com empresas, governo e instituições, criando ambientes de inovação e empresas nascentes [Audy 2006].

A aproximação da universidade com movimentos ligados a inovação é fundamental para suprir as necessidades atuais sociedade, sendo o agente responsável em transferir os resultados obtidos e visando a geração de valor econômico. A Universidade Empreendedora é um conceito indissociável do trinômio Ciência-Tecnologia-Inovação.

Para desenvolver este potencial é importante a criação de mecanismos institucionais que viabilizem o envolvimento de todos os responsáveis por esta renovação e transformação do ambiente acadêmico. O Programa de Desenvolvimento do Empreendedorismo e Criação de Startups é uma ferramenta que vem conseguindo sensibilizar um grande número de acadêmicos, prospectando propostas inovadoras e qualificando futuros empreendedores com conceitos atuais de desenvolvimento econômico e social com sustentabilidade ambiental.

A cada nova turma são avaliados os resultados obtidos e ajustes no programa podem e devem ser feitos para a melhoria na qualidade da formação empreendedora dos acadêmicos. Desde o início do programa, o departamento tem observado uma postura diferente dos acadêmicos com relação ao empreendedorismo. Antes do PDECS, o aluno tinha uma visão sobre empreendedorismo somente na própria disciplina de empreendedorismo que é ofertada no 4o ano. Como geralmente os alunos já estão atuando nas empresas de software a partir do 2o ano, isto acabava limitando em pouco tempo a possibilidade de engajar este acadêmico no desenvolvimento de novos negócios. Assim, por meio do programa o departamento possibilita despertar o perfil empreendedor logo nos primeiros anos.

Outro ponto positivo que deve ser levado em consideração, foi a maior aproximação do Departamento de Informática da Univille com a IBT - Inovaparq, o que 
estimulou outros professores a desenvolver atividades em suas disciplinas voltados ao empreendedorismo e algumas delas sendo desenvolvidas na própria incubadora, incentivando e auxiliando ainda mais na divulgação do programa e no processo empreendedor.

Considerando-se por um lado, que o programa é recente, e por outro, que o estímulo ao empreendedorismo é um processo de mudança cultural e comportamental, fica clara a necessidade de maior tempo de aplicação do programa para sensibilizar um número maior de acadêmicos do curso de Sistemas de Informação. Neste sentido, os resultados continuarão a ser mensurados e acompanhados, buscando ampliar seu impacto na comunidade acadêmica.

Atualmente é oferecida somente uma turma por ano, mas pretende-se criar uma forma de admissão contínua no programa, para que o acadêmico assim que estimulado a empreender, possa já iniciar com algum apoio da incubadora. A proposta qualifica tanto a universidade, cumprindo seu papel empreendedor, quanto a própria incubadora, que passa a atuar efetivamente como um agente de inovação, ampliando os seus limites e criando um ambiente de ideação, responsável pelo desenvolvimento de networking e compartilhamento de conhecimento para a geração de projetos inovadores comprometidos com as necessidades reais da sociedade.

\section{Referências}

ABRUC (2016). Associação brasileira das universidades comunitárias. [Online; Acessado 20-Outubro-2016].

Aguiar, R. S. (2013). O empreendedorismo em universidades. [Online; Acessado 15Junho-2016].

Audy, J. L. N. (2006). Entre a tradição e a renovação: os desafios da universidade empreendedora. A Universidade no Brasil: concepções e modelos, page 265.

Borba, E. (2015). Inovação Natural a Nova Essência do Mundo dos Negócios. Instituto Mobi.

Clark, B. R. (2003). Sustaining change in universities: Continuities in case studies and concepts. Tertiary Education and Management, 9(2):99-116.

Endeavor (2014). Empreendedorismo nas universidades brasileiras. [Online; Acessado 20-Outubro-2016].

Etzkowitz, H. (2008). The triple helix: university-industry-government innovation in action. Routledge.

Etzkowitz, H. and Viale, R. (2010). Polyvalent knowledge and the entrepreneurial university: A third academic revolution? Critical Sociology, 36(4):595-609.

Ries, E. (2014). A startup enxuta. Leya.

Romão, L. M., Provezi, J. A., Beltrão, J. A. R., and Ogê, M. (2016). O empreendedor e o empreendedorismo. Conversando sobre empreendedorismo / Collere, Vanessa de Oliveira et.al, page 172.

Souza, E. C. L. and Aquino Guimarães, T. (2005). Empreendedorismo além do plano de negócio. Atlas. 